\title{
Some fixed point theorems via partial order relations without the monotone property
}

\section{WARUT SAKSIRIKUN and NARIN PETROT}

\section{ABSTRACT.}

The main aim of this paper is to consider some fixed point theorems via a partial order relation in complete metric spaces, when the considered mapping may not satisfy the monotonic properties. Furthermore, we also obtain some couple fixed point theorems, which can be viewed as an extension of a result that was presented in [V. Berinde, Generalized coupled fixed point theorems for mixed monotone mappings in partially ordered metric spaces, Nonlinear Anal., 74 (2011), 7347-7355].

Acknowledgement. The authors would like to thank the referees for the complete reading of the first version of this work and for the pertinent suggestions allowing us to improve the presentation of the paper. This work is partially supported by the National Research Council of Thailand (Project No. R2558B005). W. Saksirikun is supported by the Thailand Research Fund through the Royal Golden Jubilee PhD Program (Grant No. PHD/0248/2553).

\section{REFERENCES}

[1] Amini-Harandi, A., Coupled and tripled fixed point theory in partially ordered metric spaces with application to initial value problem, Mathematical and Computer Modelling, vol. 57, No. 9-10, pp. 2343-2348, 2012

[2] Berinde, V., Generalized coupled fixed point theorems for mixed monotone mappings in partially ordered metric spaces, Nonlinear Anal., 74 (2011), 7347-7355

[3] Chang, S. S., Cho, Y. J. and Huang, N. J., Coupled fixed point theorem with applications, J. Korean Math. Soc., 33 (1996), No. 3, 575-585

[4] Du, W.-S., Some new results and generalizations in metric fixed point theory, Nonlinear Analysis: Theory, Method and Applications, (2010)

[5] Du, W.-S., Coupled fixed point theorems for nonlinear contractions satisfied Mizoguchi-Takahashis condition in quasiordered metric spaces, Fixed Point Theory Appl 2010, 9 (2010), Article ID 876372

[6] Gnana Bhaskar, T. and Lakshmikantham, V., Fixed point theorems in partially ordered metric spaces and applications, Nonlinear Anal., 65 (2006) 1379-1393

[7] Nieto, J. and Rodriguez-Lopez, R., Contractive mapping theorems in partially ordered sets and applications to ordinary differential equation, Order., 22, 223-239 (2005), doi: 10.1007/s11083-005-0769-0

[8] Ran, A. C. M and Reurings, M. C. B., A fixed point theorem in partially ordered sets and some applications to matrix equation, Proc. Am. Math. Soc., 132 (2004), 1435-1443

[9] Reich, S., Some problems and results in fixed point theory, in Topological Methods in Nonlinear Functional Analysis(Toronto, Ont., 1982). In Contemp Math, vol. 21 (1983) 179-187. American Mathematical Society, Providence, RI, USA

[10] Samet, B. Karapinar, E., Aydi, H. and Rajic, V., Discussion on some coupled fixed point theorems, Fixed Point Theory Appl., 50 (2013)

[11] Sintunavarat, W., Kumam, P. and Cho, Y. J., Coupled fixed point theorems for nonlinear contractions without mixed monotone property, Fixed Point Theory and Applications 2012, 2012:170

Received: 01.09.2014; In revised form: 02.03.2015; Accepted: 05.03.2015

2010 Mathematics Subject Classification. 47H10, 54H25.

Key words and phrases. Fixed point, coupled fixed point, R-function, monotone property, mixed monotone property. Corresponding author: N. Petrot; narinp@nu.ac.th 
Department of Mathematics, Faculty of Science

NARESUAN UNIVERSITY

PhitsanuloK, 65000, Thailand

E-mail address: w_saksirikun@hotmail.co.th

E-mail address: narinpenu.ac.th 